\title{
Potensi Teknis - Ekonomis Daur Ulang Efluen Air Limbah Industri Tekstil Menggunakan Aplikasi Arang Aktif
}

\section{Technical and economical potential of textile industry effluent wastewater treatment plant for water re-use using carbon active application}

Ari Christiany $^{\mathrm{a}}$, Suprihatin ${ }^{\mathrm{b}}$, Nastiti Siswi Indrasti ${ }^{\mathrm{b}}$

${ }^{a}$ Mahasiswa S2 Program Studi Pengelolaan Sumber daya alam dan Lingkungan, Institut Pertanian Bogor, Bogor, 16129, Indonesia

bDepartemen Teknologi Industri Pertanian, Fakultas Teknik Pertanian, Institut Pertanian Bogor, Bogor, 16680, Indonesia

\section{Article Info:}

Received: 22 - 04 - 2018

Accepted: 05 - 09 - 2018

\section{Keywords:}

Carbon active, textile

wastewater, water recycle, water reuse

Corresponding Author: Ari Christiany

Program Studi Pengelolaan

Sumber daya alam dan

Lingkungan, Institut Pertanian

Bogor;

Email: arichristin@yahoo.com

\begin{abstract}
The process production of textile industry especially dyeing can not be separated from the use of clean water and high wastewater pollutant produced. The study and research of potential wastewater recycling using carbon active processing have technical and economical potential to be an inspiration for industries, and the public to do waste water. The experimental application of this activated carbon using a tank size of 78 liters with 50 liter of activated carbon content, contact time 10-20 minutes. Inlet-outlet analysis can measure effectiveness of carbon active value to decrease COD (chemicals oxigen demand), colour, TDS (Total disolved solid), TSS (Total suspended solid), and $\mathrm{pH}$. Carbon active process decreased COD contamination up to $96 \%$, with value COD average 97 ppm become 5.5 ppm. Carbon active process decreased TSS up to 92\%, from average $12 \mathrm{ppm}$ become $1 \mathrm{ppm}$. This system also can decrease colour average $98 \%$, from average 226 ppm become 4 ppm. Carbon active process has little effect on TDS and pH value, but TDS and $\mathrm{pH}$ values still meet the standard. The calculation of the economic value derived from the calculation of active carbon projection, which uses a projection of $12.5 \mathrm{~m}^{3} / \mathrm{h}$, shows the cost of $3800 \mathrm{per} \mathrm{m}^{3}$. This recycling process could improve process efficiency and saved production costs, price municipal water for industrial is around 12000 per $\mathrm{m}^{3}$, which mean saved production cost around 8200 rupiahs per $\mathrm{m}^{3}$.
\end{abstract}

How to cite (CSE Style $8^{\text {th }}$ Edition):

Christiany A, Suprihatin, Indrasti NS. 2019. Potensi teknis-ekonomis daur ulang efluen air limbah industri tekstil menggunakan aplikasi arang aktif. JPSL 9(2): 229-240. http://dx.doi.org/10.29244/jps1.9.2.229-240.

\section{PENDAHULUAN}

\section{Latar Belakang}

Industri tekstil berkembang seiring dengan pertumbuhan penduduk yang pesat, teknologi proses pencelupan warna yang hingga kini masih membutuhkan air dalam jumlah yang besar menuntut konsumsi air dalam jumlah besar (Sulaksono et al. 2015). Menurut Dede (2013) kondisi keberadaan air tanah di Jawa Barat secara keseluruhan mengalami penurunan yang tinggi sedangkan setiap tahun penggunaan air tanah naik 2.5\%, hal ini memicu zona krisis pada 116 titik, dan zona rusak ada pada 560 titik (Lambok 2013).

Selain membutuhkan air yang tinggi untuk proses produksi, industri tekstil menyumbang pencemaran air sungai, karena sekitar 10-15\% dari zat warna tekstil yang digunakan terbuang bersama limbah cair (Selvam et al. 2003). Kondisi kualitas air buangan sistem pengelolaan air limbah belum bisa menghasilkan 
kualitas air sesuai parameter air bersih sesuai Permenkes No.416/1990, sehingga sulit sekali untuk digunakan sebagai air daur ulang. Sulit nya mencari referensi mengenai biaya pengelolaan limbah yang kualitas airnya mampu untuk di daur ulang mendorong adanya penelitian ini, karena referensi biaya bersifat tertutup dan tidak terpublikasi. Dengan adanya referensi biaya optimasi air limbah dengan kualitas air yang bisa di gunakan kembali, diharapkan mampu mendorong para pengusaha tekstil khusus nya di daerah Bogor untuk melihat kemungkinan investasi air limbah daur ulang namun secara ekonomis produknya tetap mempunyai daya saing global.

Penambahan sistem adsorbsi karbon aktif setelah keluaran pengolahan air limbah mempertimbangkan ketersediaan teknologi di pasaran dengan biaya investasi yang murah (Mithun 2012). Aspek lingkungan dan strategi yang dipakai untuk menghitung analisis tersebut adalah dengan melakukan evaluasi pemenuhan parameter kualitas air buangan yang dihasilkan agar mampu digunakan kembali. Adapun parameter kualitas yang diinginkan, berdasarkan hasil rata-rata kualitas air bersih yang biasa digunakan, dan sesuai dengan kebutuhan air baku adalah COD dibawah $10 \mathrm{mg} / \mathrm{l}$, Warna dibawah $30 \mathrm{mg} / \mathrm{l}$, TSS dibawah $10 \mathrm{mg} / \mathrm{l}, \mathrm{pH}$ dengan rentang 6-9, TDS dibawah $1000 \mathrm{mg} / \mathrm{l}$. Nilai perameter tersebut dibawah standard air bersih baku mutu sesuai Permenkes No.416/1990.

Zat warna adalah senyawa yang dipergunakan dalam bentuk larutan atau dispersi pada suatu bahan lain sehingga berwarna (Rambe 2009). Tingginya pemakaian zat pewarna pada kegiatan industri tertentu membawa dampak pada peningkatan jumlah bahan pencemar dalam limbah cair yang dihasilkan (Nugroho 2006). Sekitar 10000 jenis pewarna digunakan pada industri tekstil. Zat warna tekstil dapat dibedakan menjadi dua jenis berdasarkan sumbernya yaitu zat warna alami dan zat warna sintesis. Zat warna sintesis bisa dikategorikan an organik, sedang yang alami dikategorikan organik. Pencemar organik dalam zat warna tekstil alami bersifat mudah terurai dan bersifat sulit terurai. Senyawa organik biokimia sulit terurai didominasi oleh proses pengolahan air limbah tekstil dimana dapat dideteksi dengan cara spektrometri (Schröder 1996). Penelitian proses penurunan pencemar dengan menggunakan karbon aktif karena sifat karbon aktif yang memiliki daya serap pencemar organik yang sulit diuraikan dengan proses biologis biasa, ataupun sulit diikat menggunakan bahan kimia koagulan dan flokulan.

Karbon aktif merupakan arang padat yang telah diproses lebih lanjut sehingga memiliki sifat adsorben (memiliki daya serap). Kemampuan karbon aktif sebagai adsorben ditimbulkan oleh terbentuknya poripori pada arang tersebut akibat proses karbonisasi dan aktivasi. Karakterisasi karbon aktif dipengaruhi oleh jenis bahan baku dan kondisi pembuatannya (Ningrum 2008). Bahan baku yang digunakan sebagai karbon aktif adalah semua bahan yang mengandung karbon, baik yang berasal dari tumbuh-tumbuhan, binatang maupun barang tambang. Bahan-bahan tersebut yaitu berbagai jenis kayu, batu bara, tempurung kelapa, kulit biji kopi, dan lain sebagainya (Subadra 2005).

Fungsi utama karbon aktif dalam industri adalah sebagai media penjerap (Kurniawan 2004). Selain sebagai adsorben, karbon aktif dapat digunakan sebagai decolourizing (penghilang warna), deodorizing (penghilang bau), water purification (penjernihan/pemurnian air), dan waste treatment (pengolahan limbah cair atau gas) (Smisek dan Cerny 1970), juga untuk menurunkan COD. Menurut Rochma dan Titah (2017) proses adsorpsi arang aktif mampu menurunkan nilai COD mencapai 98.74\%.

Adsorpsi adalah reaksi eksoterm. Tingkat adsorpsi umumnya meningkat seiring dengan menurunnya suhu. Makin lama waktu kontak menunjukkan molekul zat terlarut yang teradsorpsi berlangsung lebih baik (Reynold 1982). Permukaan padatan yang kontak dengan suatu larutan cenderung untuk menghimpun lapisan dari molekul-molekul zat terlarut pada permukaannya akibat ketidakseimbangan gaya-gaya pada permukaan. Kapasitas adsorpsi dari karbon terhadap suatu zat terlarut tergantung pada dua-duanya, karbon dan zat terlarutnya. Kebanyakan limbah cair adalah kompleks dan bervariasi dalam hal kemampuan adsopsi dari campuran-campuran yang ada. Struktur molekul, kelarutan dan sebagainya, semuanya berpengaruh terhadap kemampuan adsorpsi. Derajat I kemungkinan adsorpsi akan terjadi dan menghasilkan hubungan kesetimbangan berkorelasi menurut hubungan empiris dari Freundlich, dan turunan Langmuir (Syauqiah et al. 2011). Menurut Syauqiah et al. (2011), Secara umum, faktor-faktor yang mempengaruhi proses adsorpsi adalah sebagai berikut: 
1) Luas permukaan. Semakin luas permukaan adsorben, maka makin banyak zat yang teradsorpsi. Luas permukaan adsorben ditentukan oleh ukuran partikel dan jumlah dari adsorben.

2) Jenis adsorbat. Peningkatan polarisabilitas adsor-bat meningkatkan kemampuan adsorpsi molekul yang mempunyai polarisabilitas yang tinggi (polar) memiliki kemampuan tarik menarik terhadap molekul lain dibandingkan molekul yang tidak dapat membentuk dipol (non polar); Peningkatan berat molekul adsorbat dapat meningkatkan kemampuan adsorpsi. Adsorbat dengan rantai yang bercabang biasanya lebih mudah diadsorbsi dibandingkan rantai yang lurus.

3) Struktur molekul adsorbat. Hidroksil dan amino mengurangi kemampuan penyisihan sedangkan Nitrogen meningkatkan kemampuan penyisihan.

4) Konsentrasi Adsorbat. Semakin besar konsentrasi adsorbat dalam larutan maka semakin banyak jumlah substansi yang terkumpul pada permukaan adsorben.

5) Temperatur Pemanasan atau pengaktifan adsorben meningkatkan daya serap adsorben terhadap adsorbat menyebabkan pori-pori adsorben lebih terbuka pemanasan yang terlalu tinggi menyebabkan rusaknya adsorben sehingga kemampuan penyerapannya menurun.

6) Waktu Kontak. Penentuan waktu kontak yang menghasilkan kapasitas adsorpsi maksimum terjadi pada waktu kesetimbangan. Waktu kesetimbangan dipengaruhi oleh:

$\checkmark$ Tipe biomasa (Jumlah dan jenis ruang pengikatan),

$\checkmark$ Ukuran dan fisiologi biomasa (aktif atau tidak aktif),

$\checkmark \quad$ Ion yang terlibat dalam sistem biosorpsi

$\checkmark$ Konsentrasi ion logam.

Arang merupakan suatu padatan berpori yang mengandung $85-95 \%$ karbon, dihasilkan dari bahanbahan yang mengandung karbon dengan pemanasan pada suhu tinggi. Arang aktif biasanya disebut karbon aktif yang dapat menjerap beberapa jenis zat di dalam cairan ataupun gas. Berarti arang aktif dapat digunakan sebagai bahan penjernih ataupun untuk menghilangkan bau busuk. Pada arang aktif terdapat banyak pori (zone) berukuran nano hingga mikrometer. Sedemikian banyaknya pori sehingga dalam satu gram arang aktif bila semua dinding rongga pori direntangkan, luas permukaannya dapat mencapai ratusan hingga ribuan meter persegi (Syauqiah et al. 2011).

Pengolahan air limbah pada PT XY menggunakan sistem biologis - kimia, kolam aerasi yang sebagai kolam biologi aerobik yang dilanjutkan proses kimia flokulasi koagulasi diharapkan mampu menurunkan pengotor air limbah dan memenuhi standar parameter baku mutu. Uji penggunaan karbon aktif dilakukan untuk mengetahui apakah penambahan karbon aktif mampu menurunkan nilai COD hingga memenuhi standar yang diiinginkan, dan menganalisis parameter dalam hal ini fisika sesuai standar baku mutu Permenkes no.32 tahun 2017, ataupun Permenkes 416/1990.

Pada tempat penelitian kondisi kualitas air buangan sistem pengelolaan menunjukkan nilai rata-rata COD 91-146 ppm, TSS sekitar 2-11 ppm, pH: 6-9 sedangkan kualitas air baku yang diinginkan COD dibawah 10 ppm, TSS dibawah 10 ppm, pH 6-8, TDS dibawah 1000 ppm, warna dibawah 10 ppm seperti rata-rata kualitas air baku yang dipakai di PT XY.

Tidak hanya secara teknis namun nilai ekonomis juga menjadi pertimbangan agar suatu teknologi daur ulang bisa diaplikasikan. Karena itu analisis biaya aplikasi penggunaan karbon aktif pada efluen instalasi pengolahan air limbah perlu dilakukan.

\section{Tujuan}

1. Mengetahui kemampuan karbon aktif dalam menurunkan nilai COD, warna, TSS, TDS dan pH pada efluen pengolahan air limbah

2. Mengetahui biaya penggunaan sistem karbon aktif

\section{METODE PENELITIAN}

Penelitian ini dilakukan pada industri tekstil di Bogor pada saluran air outlet pengolahan limbah. Pelaksanaan uji dilakukan selama 24 hari, dalam penelitian ini dianalisis COD (Chemicals oksigen demand) 
sebagai salah satu parameter air limbah dan menjadi indikator hilangnya pengotor atau menunjukkan nilai organik pada suatu kondisi air (Nugroho 2006). Warna, pH, TDS (Total dissolved solid), TSS (Total suspended solid) sebagai parameter fisika standar baku mutu (Permenkes 416/1990). Kualitas air diukur pada inlet, yaitu sebelum masuk ke tangki karbon aktif, dan pada outlet yaitu setelah melewati tangki karbon aktif pada pipa outlet. Tangki ber volume 78 liter, berisi 50 liter arang aktif, dilewati 0.18 liter/detik untuk waktu lama kontak 20 menit, atau dilewati $0.216 \mathrm{~m}^{3}$ sekali percobaan. Analisis dilakukan pada laboratorium PT XY, yaitu tempat pengambilan sampel.

Analisis parameter kualitas air setelah pengolahan karbon aktif sebagai proses adsorbsi (Anonim 2017) dilakukan setiap hari, dilakukan dengan melewatkan kedalam tangki karbon rata-rata 20 menit dengan debit 0.18 liter perdetik. sampai mencapai titik jenuh yaitu kondisi dimana karbon aktif sudah tidak mampu lagi menurunkan pengotor, dan diulangi setelah pelaksanaan pencucian atau dikenal dengan backwash. Pada umumnya pelaksanaan backwash ini dilakukan dengan menggunakan air bersih dengan membalik arah masuk air dari kondisi normal nya. Pada proses backwash ini dibutuhkan tekanan melalui pompa bertekanan, proses ini membuka pori-pori yang tertutup oleh pengotor atau lumpur (Anonim 2017). Dalam penelitian ini pencucian dilakukan dengan membuka tangki dan melakukan pencucian secara manual, hingga pengotor hilang, dan air cuci tidak keruh lagi.

Penelitian pada effluent pengolahan air limbah ini dianalisa setiap hari pada titik inlet dan outlet seperti Tabel 1.

Tabel 1 Waktu pengukuran percobaan karbon aktif

\begin{tabular}{ccc}
\hline Parameter & Titik sampling & Waktu sampling \\
\hline COD & in - out & 1 kali setiap hari \\
TSS & in - out & 1 kali setiap hari \\
TDS & in - out & 1 kali setiap hari \\
Warna & in - out & 1 kali setiap hari \\
pH & in - out & 1 kali setiap hari \\
\hline
\end{tabular}

Analisis Laboratorium dilakukan untuk mengukur kualitas awal dan kualitas air setelah melewati tangki karbon aktif. Lima parameter yang diukur adalah COD, pH, TSS, TDS, dan warna. Metode analisis menggunakan peralatan dan fasilitas yang ada di PT XY tempat penelitian dilakukan.

\section{Pengukuran COD}

Kadar COD dibaca sebagai jumlah mg oksigen per liter yang dibutuhkan untuk mengoksidasi senyawa organik dan anorganik (Yuwono dan Adinugroho 2012). Pemanasan 2 jam dilakukan bersama proses oksidasi oleh potassium dikromat. Reaksi oksidasi senyawa organik mereduksi ion dikromat menjadi ion kromik yang berwarna hijau. Unsur perak dalam reagent berfungsi sebagai katalis dan ion merkuri digunakan untuk mengomplekskan senyawa pengganggu klorida. Penetapan kadar dilakukan oleh spektrofotometer pada panjang gelombang $620 \mathrm{~nm}$. Alat yang dipakai Spektrofotometer DR/2010, COD Reagent vial, Light Shield, COD Reaktor, Pipet volumetrik $2 \mathrm{~mL}$, gelas beker $500 \mathrm{~mL}$, botol semprot, rak tabung reaksi, batang pengaduk, dan di butuhkan bahan larutan sampel, aquades, COD digestion reagent (0 -1 $500 \mathrm{mg} / \mathrm{l} \mathrm{COD)}$.

\section{Pengukuran $\mathrm{pH}$}

Sensor probe (glass elektrode) dari $\mathrm{pH}$ meter melakukan pembacaan $\mathrm{pH}$ berdasarkan jumlah ion $\mathrm{H}_{3} \mathrm{O}^{+}$ dalam larutan. Menggunakan pH meter thermo-orion A211, gelas beker $500 \mathrm{ml}$, dan botol semprot.

\section{Pengukuran TSS}

Penetapan suspended solid dilakukan tanpa menggunakan teknik filtrasi terlebih dahulu karena yang ingin dicari ialah kadar suspended solid. Teknik gravimetri dilakukan apabila ingin mengetahui suspended 
solid yang ada pada sampel (Yuwono dan Adinugroho 2012). Penetapan kadar dilakukan oleh spektrofotometer pada panjang gelombang $810 \mathrm{~nm}$ dengan metode Spektrofotometri (Photometric methode, non filtrable residue). Alat yang digunakan Spektrofotometer DR/2010, sample cell $25 \mathrm{~mL}$, light shield, gelas piala $500 \mathrm{ml}$, botol semprot, Pipet volume/ Pipet mohr.

\section{Pengukuran TDS}

Penetapan TDS dilakukan berdasarkan sensor sensitif dari probe TDS meter yang mendeteksi jumlah dari total padatan terlarut (Yuwono dan Adinugroho 2012) dalam sampel atau pun jumlah non padatan seperti mikroorganisme dalam sampel. Alat yang digunakan TDS meter, gelas beker $500 \mathrm{ml}$, botol semprot.

\section{Pengukuran Warna}

Penetapan turbidity atau warna dilakukan berdasarkan hasil penyebaran dan penyerapan cahaya oleh partikel dalam sampel dan jumlahnya ditetapkan berdasarkan ukuran, bentuk, warna, dan bias dari sampel. Penetapan kadar dilakukan dengan menggunakan spektrofotometer pada panjang gelombang $860 \mathrm{~nm}$, menggunakan Spektrofotometri (Attenuated Radiation) (Yuwono dan Adinugroho 2012).

\section{HASIL DAN PEMBAHASAN}

Air daur ulang yang diharapkan memenuhi kualitas yang diinginkan, setara dengan kualitas air baku rata-rata dari campuran air sumur dan atau air bersih PDAM. Air baku sebelum dipakai dalam proses produksi pencelupan akan diproses terlebih dahulu pada sistem pengolahan air bersih yang dimiliki PT XY, yaitu proses demineralisasi dan reverse osmosis. Kualitas yang diinginkan untuk dapat memenuhi proses tersebut dapat dilihat seperti Tabel 2. Selain standard acuan juga bisa melihat standar Permenkes No 416 Tahun 1990.

Tabel 2 Acuan kualitas air olahan

\begin{tabular}{ccc}
\hline Parameter uji & Target & $\begin{array}{c}\text { Baku mutu sesuai } \\
\text { Permenkes No.416/1990 }\end{array}$ \\
\hline COD & $10 \mathrm{mg} / \mathrm{l}$ & - \\
TDS & $1000 \mathrm{ppm}$ & $1500 \mathrm{ppm}$ \\
Kekeruhan (TSS) & $10 \mathrm{mg} / \mathrm{l}$ & $25 \mathrm{mg} / \mathrm{l}$ \\
Warna & $30 \mathrm{Ntu}$ & $50 \mathrm{Ntu}$ \\
$\mathrm{pH}$ & $6-9$ & $6-9$ \\
\hline
\end{tabular}

Air inlet percobaan karbon aktif adalah keluaran air pengolahan air limbah pada PT XY. Sistem yang digunakan dalam pengolahan air limbah adalah pengolahan biologis - kimia, kolam aerasi ebagai kolam biologi aerobik yang dilanjutkan proses kimia flokulasi. Dari analisis pendahuluan didapatkan nilai COD awal limbah PT XY rata-rata 1400 ppm, dapat diturunkan menjadi rata-rata 520 ppm, dan menjadi ratarata 97 ppm setelah melewati proses koagulasi dan flokulasi. Pengukuran yang dilakukan setiap hari pada proses outlet pengolahan arang aktif dapat dilihat pada Tabel 3.

\section{Analisis COD}

Karbon aktif sangat efektif dalam menurunkan bahan-bahan organik dan an-organik, seperti Escherechia coli, parasit, logam-logam (Utami 2017). COD adalah jumlah oksigen yang dibutuhkan untuk mengoksidasi zat-zat organik yang terdapat dalam limbah cair dengan memanfaatkan oksidator kalium dikromat sebagai sumber oksigen (Rochma dan Titah 2017). Angka COD merupakan ukuran bagi pencemaran air oleh zat organik yang secara alamiah dapat dioksidasi melalui proses biologis dan dapat menyebabkan berkurangnya oksigen terlarut dalam air. 
Tabel 3 Hasil Percobaan penggunaan karbon aktif effluent pengolahan limbah PT XY

\begin{tabular}{|c|c|c|c|c|c|c|c|c|c|c|}
\hline Parameter & $\begin{array}{l}\text { COD } \\
\text { Inlet }\end{array}$ & $\begin{array}{l}\text { COD } \\
\text { Outlet }\end{array}$ & $\begin{array}{c}\text { Warna } \\
\text { Inlet }\end{array}$ & $\begin{array}{l}\text { Warna } \\
\text { Outlet }\end{array}$ & $\begin{array}{c}\mathrm{pH} \\
\text { Inlet }\end{array}$ & $\begin{array}{c}\mathrm{pH} \\
\text { Outlet }\end{array}$ & $\begin{array}{l}\text { TDS } \\
\text { Inlet }\end{array}$ & $\begin{array}{l}\text { TDS } \\
\text { Outlet }\end{array}$ & $\begin{array}{l}\text { TSS } \\
\text { Inlet }\end{array}$ & $\begin{array}{c}\text { TSS } \\
\text { Outlet }\end{array}$ \\
\hline Satuan & $\mathrm{mg} / \mathrm{l}$ & $\mathrm{mg} / \mathrm{l}$ & TCU & TCU & & & $\mathrm{mg} / \mathrm{l}$ & $\mathrm{mg} / \mathrm{l}$ & $\mathrm{mg} / \mathrm{l}$ & $\mathrm{mg} / \mathrm{l}$ \\
\hline Hari 1 & 99 & 22 & 226 & 12 & 7.4 & 8.17 & 712 & 680 & 7 & 1 \\
\hline Hari 2 & 92 & 3 & 241 & 0 & 5.94 & 6.1 & 726 & 700 & 6 & 1 \\
\hline Hari 3 & 93 & 1 & 198 & 3 & 5.56 & 5.8 & 682 & 690 & 12 & 1 \\
\hline Hari 4 & 96 & 1 & 203 & 1 & 5.65 & 5.7 & 754 & 730 & 14 & 1 \\
\hline Hari 5 & 107 & 0 & 223 & 4 & 5.61 & 5.9 & 678 & 674 & 12 & 1 \\
\hline Hari 6 & 102 & 3 & 245 & 2 & 5.87 & 7.2 & 720 & 710 & 15 & 1 \\
\hline Hari 7 & 98 & 6 & 267 & 2 & 5.65 & 6.2 & 690 & 720 & 17 & 1 \\
\hline Hari 8 & 89 & 8 & 208 & 10 & 5.53 & 5.8 & 688 & 699 & 6 & 1 \\
\hline Hari 9 & 86 & 12 & 220 & 38 & 5.76 & 6.02 & 623 & 684 & 9 & 2 \\
\hline Hari 10 & 92 & 38 & 220 & 45 & 5.48 & 5.8 & 636 & 690 & 12 & 3 \\
\hline Hari 11 & 98 & 42 & 240 & 30 & 5.21 & 5.7 & 750 & 734 & 11 & 2 \\
\hline \multicolumn{11}{|c|}{ Pencucian karbon aktif } \\
\hline Hari 1 & 88 & 1 & 184 & 2 & 5.95 & 6.05 & 690 & 698 & 6 & 1 \\
\hline Hari 2 & 94 & 1 & 220 & 1 & 6.07 & 7.36 & 645 & 660 & 7 & 2 \\
\hline Hari 3 & 92 & 4 & 240 & 1 & 6.04 & 7.33 & 690 & 680 & 6 & 1 \\
\hline Hari 4 & 86 & 2 & 245 & 2 & 6 & 7.33 & 702 & 700 & 12 & 1 \\
\hline Hari 5 & 88 & 3 & 196 & 2 & 6.03 & 6.96 & 700 & 704 & 14 & 2 \\
\hline
\end{tabular}

Penurunan COD signifikan pada percobaan ini. Penelitian ini menunjukkan karbon aktif mampu menurunkan angka COD dengan proses adsorpsinya, yaitu menjerap zat-zat organik (Rochma dan Titah 2017).

Pada hari pertama nilai COD mungkin tidak di bawah $10 \mathrm{mg} / 1$, hanya turun ke angka $22 \mathrm{mg} / \mathrm{l}$ dari inlet $99 \mathrm{mg} / \mathrm{l}$, menunjukkan daya jerap arang aktif kurang sempurna, karena pada hari kedua sudah terlihat penurunan di bawah $10 \mathrm{mg} / \mathrm{l}$ yaitu $3 \mathrm{mg} / \mathrm{l}$, dari $92 \mathrm{mg} / \mathrm{l}$. Hari ke tiga hingga hari ke 8 menunjukkan karbon aktif mampu menurunkan COD hingga di bawah $10 \mathrm{mg} / \mathrm{l}$ seperti standar yang diinginkan.

Pada hari pertama terindikasi arang aktif belum teraktivasi dengan sempurna, walaupun dalam proses penyediaan bahan baku nya arang aktif yang dipakai adalah jenis arang aktif siap pakai atau sudah diaktivasi.

Menurut Prasetyo et al. (2011) aktivasi arang secara kimia bisa menggunakan $\mathrm{NaCl}$ atau garam, sedang proses pembersihan awal karbon aktif hanya dicuci menggunakan air bersih. Kurang nya daya jerap pada hari pertama bisa ditutupi dengan naiknya energi aktivasi arang aktif setelah dialiri air effluent, yang mungkin mengandung garam atau ion yang mampu meningkatkan aktivasi arang aktif (Prasetyo et al. 2011). Hari ke sepuluh menunjukkan COD kembali tidak memenuhi standar yang diinginkan yaitu dari COD inlet 92 hanya mampu diturunkan ke $38 \mathrm{mg} / \mathrm{l}$, dan dari 98 menjadi $42 \mathrm{mg} / \mathrm{l}$. Dari hasil analisis menunjukkan hari ke-9 perlu dilakukan backwash untuk menormalkan fungsi kinerja karbon aktif. Proses penjerapan zat-zat oleh pori-pori karbon aktif tertutup oleh organik berlebih. Hal ini terlihat sebelum proses pencucian, karbon aktif tertutup lumpur. Setelah backwash, karbon aktif tidak tertutup lumpur, dan menunjukkan COD kembali turun di bawah $10 \mathrm{mg} / \mathrm{l}$. Untuk Hasil analisis lengkap COD dapat dilihat pada Gambar 1. 


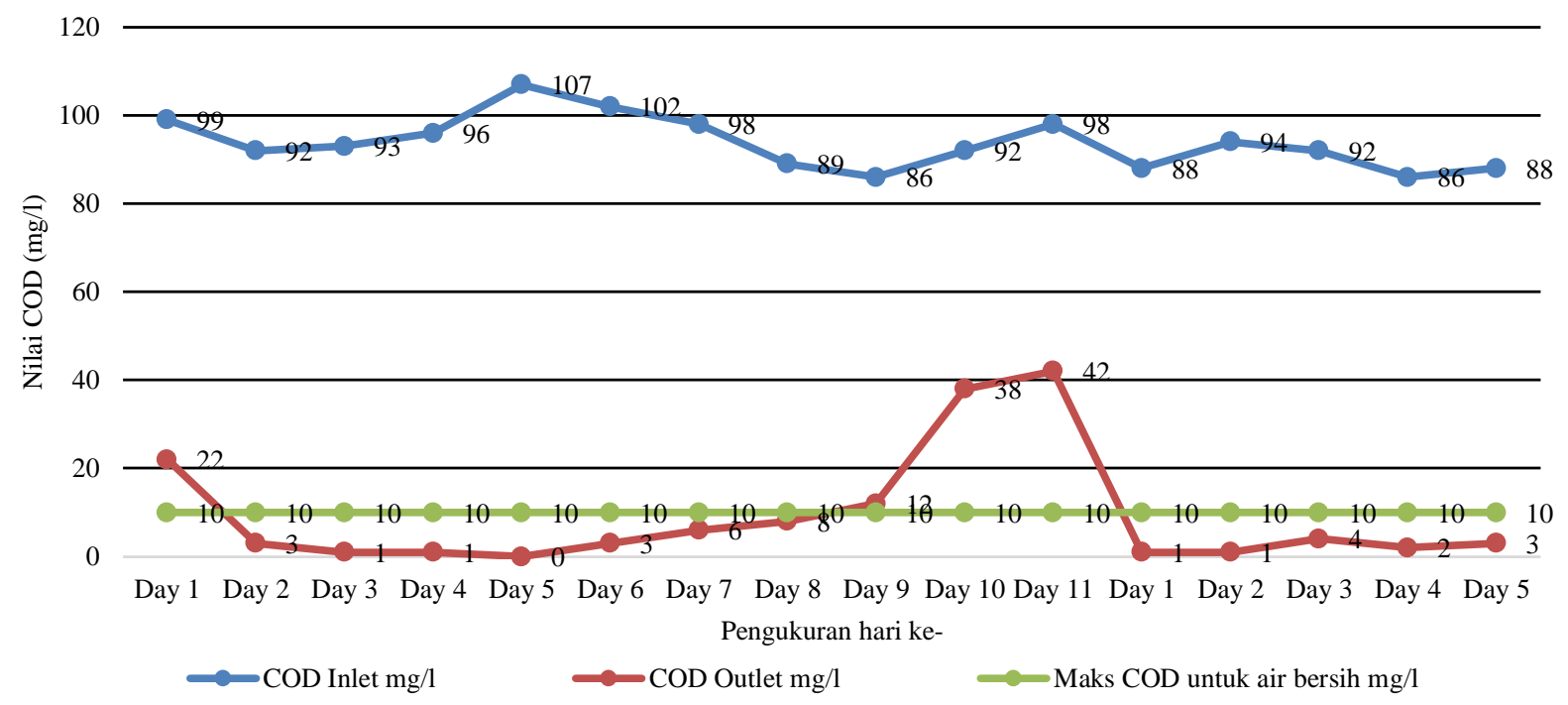

Gambar 1 Kemampuan karbon aktif dalam menurunkan COD

\section{Analisis TSS}

Zat yang tersuspensi biasanya terdiri dari zat organik dan anorganik yang melayang-layang dalam air, secara fisika zat ini sebagai penyebab kekeruhan pada air. Karbon aktif sangat efektif dalam menurunkan bahan-bahan organik dan an-organik (Utami 2017). Proses filtrasi karbon aktif ini mampu menangkap zatzat melayang yang dibaca sebagai TSS. Hasil analisis menunjukkan TSS mencapai target yang diinginkan yaitu di bawah 5 ppm. TSS inlet sendiri ada pada range 6-17. Dari hari pertama hingga hari ke sembilan angka TSS ditunjukan oleh angka $1 \mathrm{mg} / \mathrm{l}$. Kenaikan nya pun tidak signifikan yaitu ke angka 2 dan $3 \mathrm{mg} / \mathrm{l}$. Hal ini menunjukkan karbon aktif pada effluent pengolahan limbah efektif untuk menurunkan TSS hingga di bawah $5 \mathrm{mg} / \mathrm{l}$. Hasil analisis TSS dapat dilihat pada Gambar 2.

\section{Analisis TDS}

TDS adalah singkatan dari Total Dissolve Solid yang dalam Bahasa Indonesia berarti Jumlah Zat Padat Terlarut. TDS merupakan indikator dari jumlah partikel atau zat tersebut, baik berupa senyawa organik maupun non-organik. Pengertian terlarut mengarah kepada partikel padat di dalam air yang memiliki ukuran di bawah 1 nano-meter. Satuan yang digunakan biasanya ppm (part per million) atau yang sama dengan miligram per liter (mg/l) untuk pengukuran konsentrasi massa kimiawi yang menunjukkan berapa banyak gram dari suatu zat yang ada dalam satu liter dari cairan. Zat atau partikel padat terlarut yang ditemukan dalam air dapat berupa natrium (garam), kalsium, magnesium, kalium, karbonat, nitrat, bikarbonat, klorida dan sulfat (Yuwono dan Adinugroho 2012). Pada percobaan ini tidak menunjukkan karbon aktif mampu menurunkan TDS. Angka penurunan TDS tidak signifikan, contoh pada hari pertama TDS inlet 712 ppm hanya mampu turun ke angka 680 ppm, sedang pada hari kedua juga turun ke 700 dari 726 ppm. Analisis hingga hari ke sepuluh pun tidak menunjukkan karbon akif mampu menurunkan total kandungan terlarut. Dapat disimpulkan bahwa karbon aktif tidak bisa menjerap zat organik maupun organik yang ukuran nya bawah 1 nano-meter. Nilai TDS yang masih dibawah 1000 ppm menunjukkan bahwa air effluent masih bisa digunakan sebagai air baku. Hasil analisis TDS dapat dilihat pada Gambar 3. 


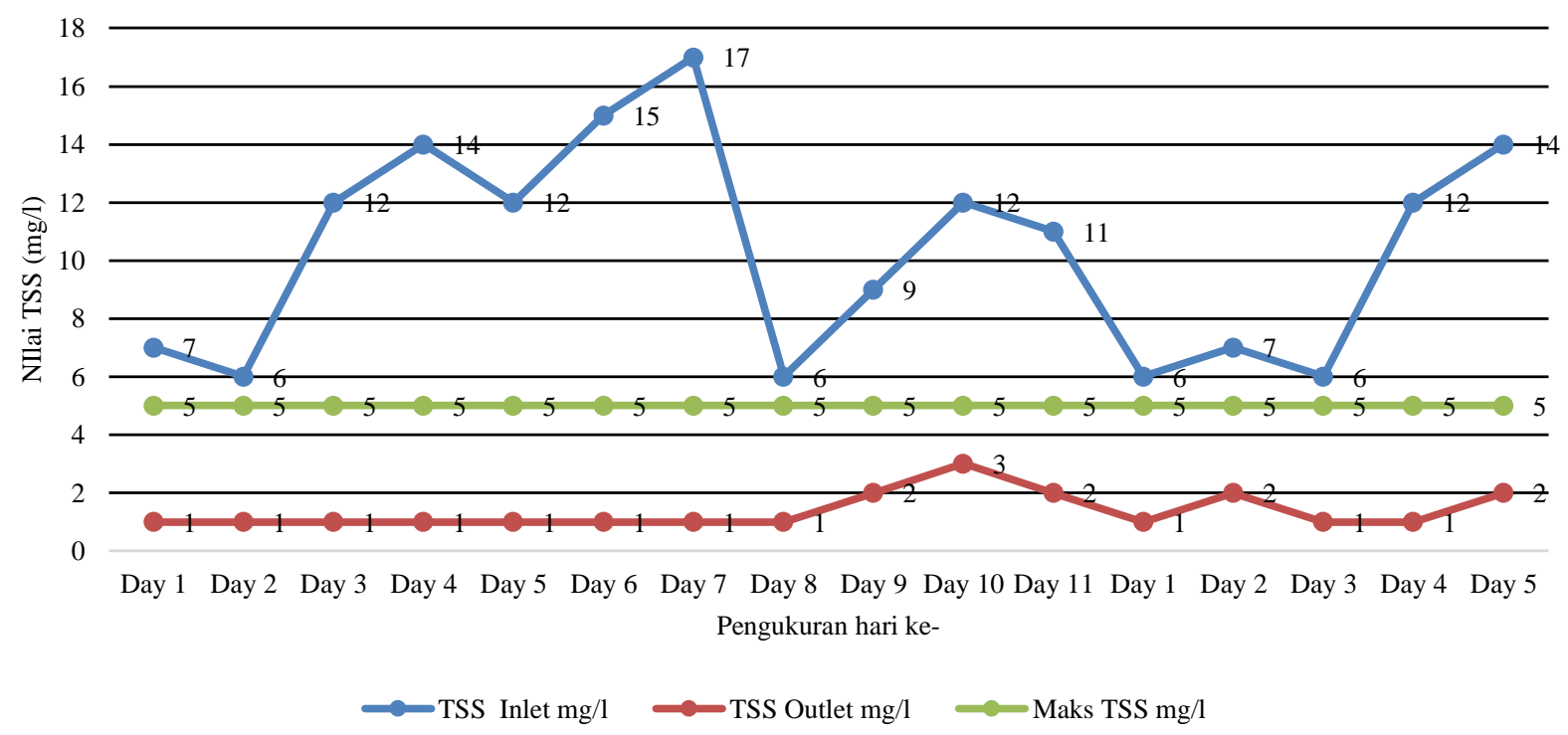

Gambar 2 Kemampuan karbon aktif dalam menurunkan TSS

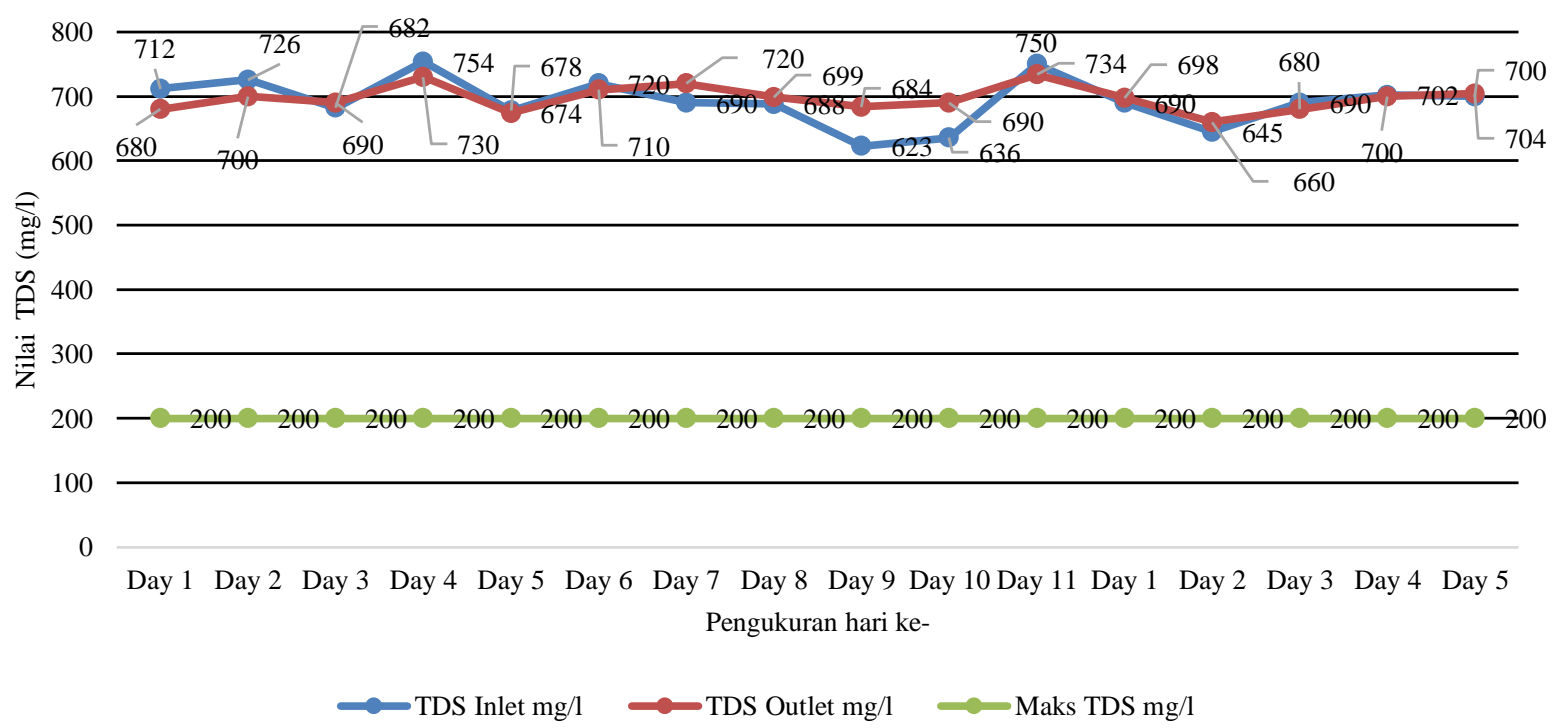

Gambar 3 Kemampuan karbon aktif dalam menurunkan TDS

\section{Analisis Warna}

Warna pada air disebabkan adanya pembusukan proses organik, warna zat-zat logam seperti besi, mangan, dan zat-zat lain (Utami 2017). Pada analisis warna trend menunjukkan selaras dengan kondisi COD, warna mengalami penurunan signifikan hingga di bawah target yaitu 10 TCU. Kondisi penurunan warna oleh proses adsorpsi karbon aktif dimana zat-zat organik dan kandungan beberapa zat lain yang menghasilkan warna mampu diserap oleh karbon aktif (Sri et al 2010). Nilai warna dan COD menunjukkan penurunan signifikan dari angka 241 menjadi $0 \mathrm{mg} / \mathrm{l}$, dari 198 pada hari ketiga menjadi 3mg/l, sedang pada hari keempat dari 203 menjadi $1 \mathrm{mg} / \mathrm{l}$. Hari kedelapan menunjukkan mulai meningkat dimana inlet 208 turun menjadi $10 \mathrm{mg} / \mathrm{l}$, demikian hari kesembilan hanya mampu diturunkan di angka $38 \mathrm{mg} / \mathrm{l}$. Pelaksanaan backwash membuat kondisi kinerja karbon aktif kembali mampu diturunkan sesuai target. Hasil analisis TDS dilihat pada Gambar 4. 


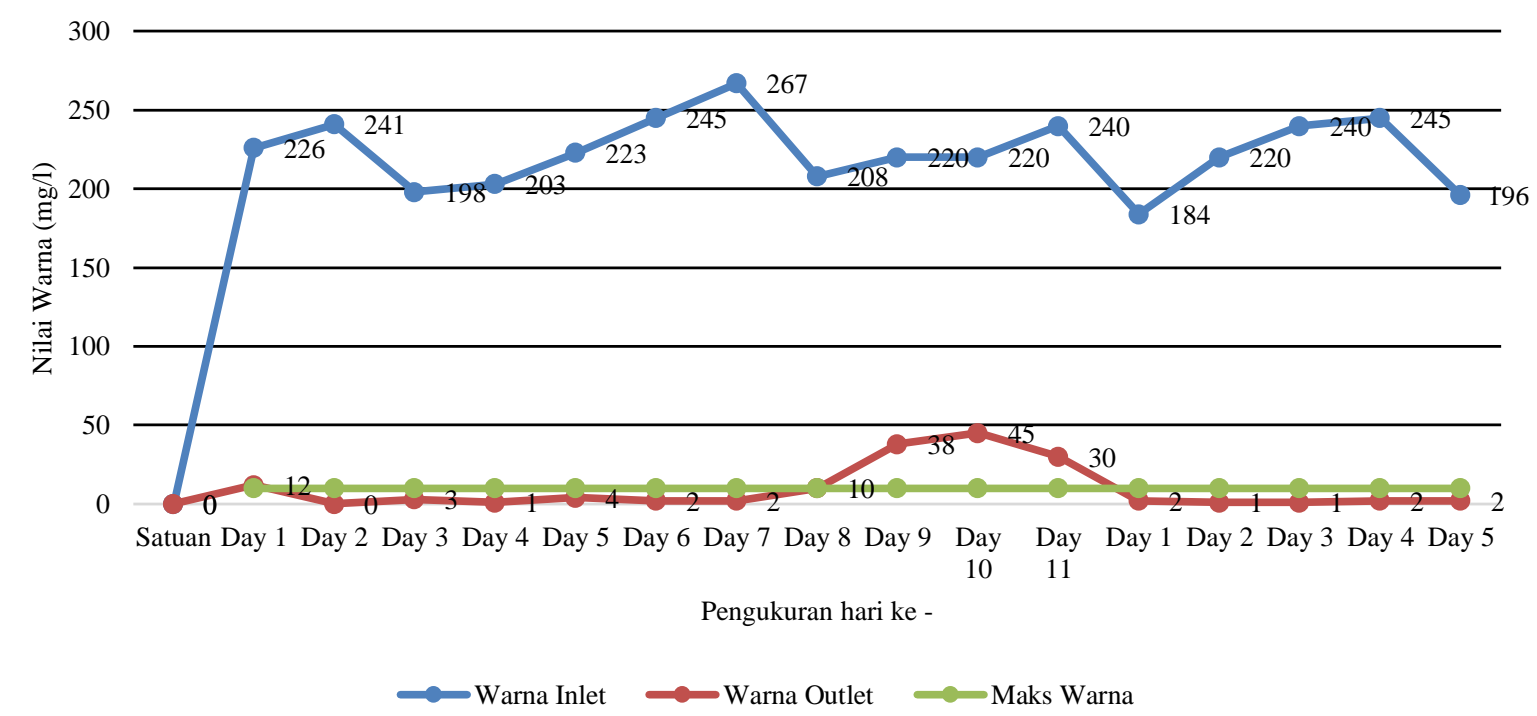

Gambar 4 Kemampuan karbon aktif dalam menurunkan Warna

\section{Analisis pH}

Tinggi rendahnya $\mathrm{pH}$ dipengaruhi oleh fluktuasi kandungan karbondioksida atau $\mathrm{CO}_{2}$, serta tingkat alkalinitas (Rachmawati et al.). Alkalinitas secara umum menujukkan konsentrasi basa atau bahan yang dapat menetralisir tingkat keasaman. Semakin tinggi alkalinitas semakin rendah kadar $\mathrm{CO}_{2}$ yang bebas dalam larutan, campuran atau badan air (Safitri dan Putri 2016). Analisis pH pada penelitian ini, tidak terjadi perubahan signifikan antara $\mathrm{pH}$ inlet dan $\mathrm{pH}$ outlet. Tidak banyak perubahan $\mathrm{pH}$ menunjukkan karbon aktif tidak berpengaruh terhadap tingkat alkalinitas (Safitri dan Putri 2016), pH yang dihasilkan setelah proses karbon aktif menunjukkan hampir sama dengan effluent yang ada. Pada penelitian ini, $\mathrm{pH}$ cukup rendah dikarenakan $\mathrm{pH}$ effluent rendah. Pada proses kimia sebelum keluar dari pengolahan limbah ada penggunaan bahan kimia yang ber based aluminium sulfat mempunyai sifat menurunkan $\mathrm{pH}$ di bawah 5. Proses kimia ini membutuhkan $\mathrm{pH}$ yang rendah karena reaksi kerja koagulasi aluminium sulfat ada diantara $\mathrm{pH} 3.8-6$. Hasil analisis $\mathrm{pH}$ dapat dilihat pada Gambar 5.

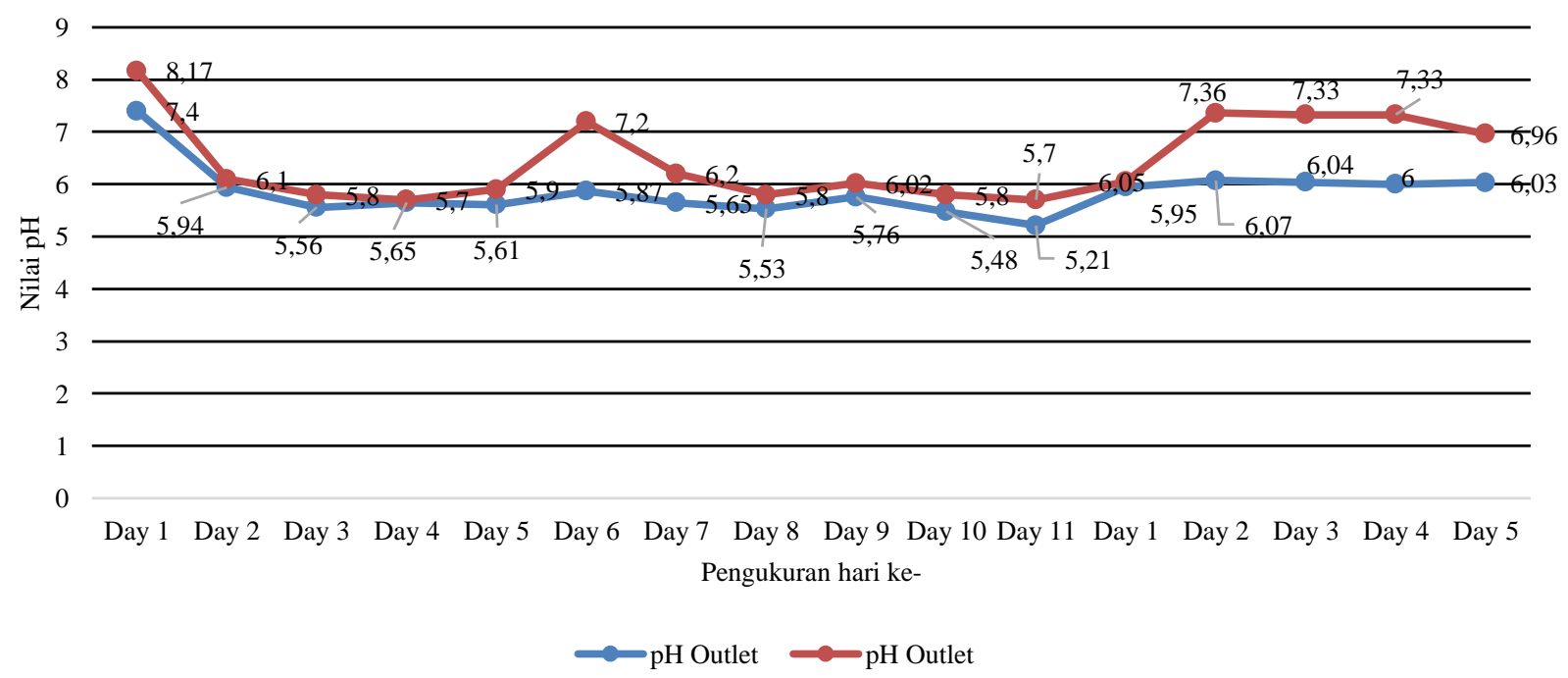

Gambar 5 Nilai pH penelitian karbon aktif 
Secara keseluruhan penggunaan karbon aktif pada effluent pengolahan air limbah mampu menurunkan kualitas air limbah menjadi air baku yang siap diolah untuk digunakan kembali sebagai water reuse, recycling. Rata-rata kinerja karbon aktif bisa digambarkan melalui persentase penurunan COD setelah penggunaan karbon (Siregar et al. 2015), yang digambarkan pada Tabel 4. Persentase penurunan COD pada air limbah setelah penggunaan karbon aktif. Dapat dilihat rata-rata performance adalah 96\% dengan waktu jenuh 8 hari.

Tabel 4 Persentase penurunan COD setelah tangki Karbon aktif

\begin{tabular}{cccc}
\hline Parameter & $\begin{array}{c}\text { COD } \\
\text { Inlet }\end{array}$ & $\begin{array}{c}\text { COD } \\
\text { Outlet }\end{array}$ & \% Penurunan COD \\
\hline Satuan & $\mathrm{mg} / \mathrm{l}$ & $\mathrm{mg} / \mathrm{l}$ & \\
\hline Hari 2 & 92 & 3 & $97 \%$ \\
Hari 3 & 93 & 1 & $99 \%$ \\
Hari 4 & 96 & 1 & $99 \%$ \\
Hari 5 & 107 & 0 & $100 \%$ \\
Hari 6 & 102 & 3 & $97 \%$ \\
Hari 7 & 98 & 6 & $94 \%$ \\
Hari 8 & 89 & 8 & $91 \%$ \\
\hline Hari 1 & & Pencucian arang aktif & \\
Hari 2 & 88 & 1 & $99 \%$ \\
Hari 3 & 94 & 1 & $99 \%$ \\
Hari 4 & 92 & 4 & $96 \%$ \\
Hari 5 & 86 & 2 & $97 \%$ \\
\hline
\end{tabular}

Tabel 5 Perkiraan total biaya pengolahan air buangan menggunakan karbon aktif

\begin{tabular}{ccccccc}
\hline \multirow{2}{*}{ Proses } & $\begin{array}{c}\text { Biaya } \\
\text { Bahan } \\
\text { Kimia }\end{array}$ & $\begin{array}{c}\text { Biaya } \\
\text { Elektrik }\end{array}$ & $\begin{array}{c}\text { Biaya } \\
\text { Investasi** }\end{array}$ & $\begin{array}{c}\text { Biaya *** penggantian } \\
\text { karbon aktif }\end{array}$ & Total & Total / m ${ }^{3}$ \\
\hline $\begin{array}{c}\text { Karbon } \\
\text { aktif }\end{array}$ & $\begin{array}{c}\text { Rp/ Bulan } \\
1112400\end{array}$ & $\begin{array}{c}\text { Rp/Bulan } \\
335420\end{array}$ & $\begin{array}{c}\text { Rp/Bulan } \\
3333333\end{array}$ & 9000000 & $\begin{array}{c}\text { Rp/Bulan } \\
\text { Rp }\end{array}$ & $\begin{array}{c}\text { R } 381154 \\
3828\end{array}$ \\
\hline
\end{tabular}

**) Break even point/Titik Impas 5 tahun

***) Penggantian karbon aktif diprediksi 6 bulan sekali

\section{Analisis biaya}

Penelitian ini mempertimbangkan prespektif ekonomi, prespektif efesiensi, prespektif ekologi (Mithun 2012). Prespektif efisiensi, yaitu Efisiensi pengolahan limbah yang diperkirakan oleh persentase pengurangan parameter seperti COD, TSS, TDS, Warna dan parameter lainnya. Prespektif ekologi, dalam hal ini dilihat dari kemampuan sistem untuk mendaur ulang limbah menjadi air daur ulang untuk mengurangi cemaran limbah ke lingkungan, dimana airnya dapat digunakan kembali sehingga mengurangi penggunaan air bawah tanah, yang berarti menjaga penggunaan sumber daya air yang kian lama kian terbatas (Mithun 2012).

Prespektif ekonomi, artinya pengolahan limbah dengan metode yang efektif dari segi biaya termasuk biaya investasi yaitu pembuatan tangki, pompa dorong dan pompa cuci atau backwash, perpipaan dan pondasi konstruksi. Selain biaya investasi análisis juga dilakukan untuk biaya operasi dan perawatan, konsumsi bahan kimia, operasional elektrik. Analisis biaya yang dibutuhkan untuk mendapatkan pengolahan limbah dengan hasil yang maksimum tersebut telah digambarkan secara detail sesuai Tabel 5. Analisis biaya 
air dengan sistem karbon aktif. Dengan perhitungan asumsi tangki yang dipakai mempunyai laju 10-12.5 $\mathrm{m}^{3} / \mathrm{jam}$, dengan volume arang aktif dalam tangki adalah 1200 liter arang aktif, masa operasi 5-8 jam per hari penggantian karbon aktif diprediksi 6 bulan sekali, dan masa balik modal investasi 5 tahun. Biaya bahan kimia dihitung dari perhitungan kebutuhan klorinasi pada proses keluaran karbon aktif. Biaya elektrik dihitung dari kebutuhan listrik untuk menjalankan pompa backwash dan pompa dosis. Secara keseluruhan selang penambahan karbon aktif membutuhkan biaya 3828 rupiah per $\mathrm{m}^{3}$

\section{SIMPULAN}

Berdasarkan hasil penelitian serta pembahasan yang dijabarkan secara detail dapat ditarik kesimpulan. Karbon aktif menunjukkan efektif mengolah keluaran air limbah dan mampu menurunkan COD dengan persentase kemampuan rata-rata 96\%, kemampuan menurunkan TSS $92 \%$ dan warna $98 \%$. Waktu jenuh 8 hari. Biaya yang dibutuhkan untuk mengolah air effluent dengan desain $12.5 \mathrm{~m}^{3} / \mathrm{jam}$, masa operasi $8-10$ jam perhari, adalah 3828 rupiah per $\mathrm{m}^{3}$. Biaya pembelian air baku PDAM untuk proses industri 12000 per $\mathrm{m}^{3}$, menunjukkan penghematan biaya hingga 8000 rupiah per meter kubik.

\section{UCAPAN TERIMA KASIH}

Ucapan terimakasih disampaikan kepada PT XY - Bogor, selaku penyedia data dan tempat uji coba dilangsungkan.

\section{DAFTAR PUSTAKA}

Anonim. 2017. Activated carbon filter. Tersedia pada: http://www.waterprofessionals.com/learningcenter/activated-carbon-filters; [diakses 22 October 2017].

Dede A. 2013. Ulasan Program Pendayagunaan Konservasi Air Tanah Dinas ESDM Kab Bogor dalam Berita. Bogor.

Lambok H. 2013. Pembahasan Pengelolaan Air Tanah Di Indonesia Konservasi Air Tanah Berbasis Cekungan Air Tanah Area Jawa Barat [buku laporan].

Mithun R. 2012. Biological Treatment of Textile Effluents Best adoptable option results in cost \& environment savings with outstanding treatment efficiency. Tersedia pada: https://textiletoday.com.bd/biological-treatment-of-textile-effluents-best-adoptable-option-results-incost-environment-savings-with-outstanding-treatment-efficiency/; [diakses 2017 April 15].

Nugroho A. 2006. Bioindikator Kualitas Air [tesis]. Jakarta: Universitas Trisakti.

Prasetyo A, Yudi A, Astuti RN. 2011. Adsorpsi metilen blue pada karbon aktif dari Ban bekas dengan Variasi konsentrasi $\mathrm{NaCl}$ pada suhu pengaktifan $600^{\circ} \mathrm{C}$ dan $650^{\circ} \mathrm{C}$. Jurnal Neutrino. 4(1).

Rachmawati SW, Iswanto B, Winarni. 2009. Pengaruh pH Pada Proses Koagulasi Dengan Koagulan Aluminium Sulfat Dan Ferri Klorida. Jurnal Teknik Lingkungan. 5(2):40-45.

Rochma N, Titah HS. 2017. Penurunan BOD dan COD Limbah cair industri Batik Menggunakan Karbon aktif melalui Proses Adsorpsi Secara Batch. Jurnal Teknik ITS. 6(2).

Safitri M, Putri MR. 2016. Kondisi Keasaman (pH) Laut Indonesia. Jurnal Institute Teknologi Bandung. Jbptitb. pp22609-9.

Schröder HR. 1996. Non- Biodegradable wastewatercompunds treated by Ozone or Ozone/UV- Conversion monitoring by substance specific analysis and biotoxicity testing. Water Science and Technology. 50(5):329-334

Selvam, Swaminathan K, Chae KS. 2003. Decolourization of azo dyes and a dye industry effluent by a white rot fungus Thelephora sp. Journal Bioresour Technology. 88(2):115-9.

Siregar RD, Zaharah TA, Wahyuni N. 2015. Penurunan Kadar COD (Chemicals Oxigen Demand) limbah cair industri kelapa sawit menggunakan arang aktif biji kapuk (Celba Petandra). Universitas Tanjungpura. JKK. 4(2).

Smisek M, Cerny S. 1970. Activated Carbon Manufacture, Properties and Aplication Institute of Physical Chemistry. Czecosloval Academy of Sciennce-Prague Anal Chem Book. 42(14):81A-81A. 
Sri M, Djarwanti, Sartamtomo, Yuliastuti R, Yuliasni R. 2010. Peningkatan kinerja lumpur aktif dengan penambahan karbon aktif dalam pengolahan air limbah industry tekstil pewarnaan dengan zat warna indigo dan sulfur. Jurnal Riset Industri. 4(1):23-33.

Sulaksono A, Effendi H, Kurniawan B. 2015. Kajian Beban Pencemaran Limbah Cair Industri Kecil Menengah (IKM) Batik klaster Trusmi Kabupaten. 5(1).

Surat Keputusan Kementerian Kesehatan Republik Indonesia. 1990. Peraturan Kementrian Kesehatan Nomor 416/ PER/IX Tahun 1990 Mengenai Standar Baku Mutu Kesehatan Lingkungan dan Syaratsyarat dan Pengawasan Kualitas Air [diakses 3 September 1990].

Surat Keputusan Kementrian Lingkungan Hidup Republik Indonesia. 2014. Peraturan Kementrian Lingkungan Hidup Nomor 5 Tahun 2014 Mengenai Baku Mutu Air Limbah [diakses 25 Oktober 2014].

Surat Keputusan Menteri Kesehatan Republik Indonesia. 2017. Peraturan Kementrian Kesehatan Nomor 32 Tahun 2017 Mengenai Standar Baku Mutu Kesehatan Lingkungan dan persyaratan air untuk keperluan Higiene, sanitasi, Kolam Renang, Solus per aqua, dan Pemandian umum [diakses 20 Juni 2017].

Syauqiah I, Amalia M, Hetty A, Kartini. 2011. Analisis Variasi waktu dan kecepatan pengaduk pada Proses Adsorpsi Limbah Logam berat dengan Arang Aktif. Jurnal Infoteknik. 12(1).

Utami, AR. 2017. Pengolahan limbah cair laundry dengan menggunakan Biosand Filter dan Activated Carbon. Jurnal Untan. 13(1).

Yuwono, R. dan Adinugroho E. 2012. Buku pegangan Manajer Pengendalian Pencemaran Air Ed ke-2. Bandung: IATPI. 